\title{
Disponibilidade e qualidade do capim-elefante com e sem irrigação adubado com nitrogênio e potássio na estação seca ${ }^{1}$
}

\author{
Claudio Mistura ${ }^{2}$, Jailson Lara Fagundes ${ }^{3}$, Dilermando Miranda da Fonseca ${ }^{4}$, Luciano de Melo \\ Moreira ${ }^{5}$, Cláudio Manoel Teixeira Vitor ${ }^{6}$, Domicio do Nascimento Júnior ${ }^{4}$, José Ivo Ribeiro Júnior ${ }^{7}$ \\ ${ }^{1}$ Pesquisa financiada pela FAPEMIG, CAPES e UFV, Viçosa - MG. \\ 2 Departamento de Tecnologia e Ciências Sociais - DTCS - Universidade do Estado da Bahia - UNEB, Campus III, Juazeiro - BA. \\ ${ }^{3}$ Pólo Regional de Desenvolvimento Tecnológico do Agronegócio da Alta Paulista, Agência Paulista de Tecnologia e Agronegócio. \\ ${ }^{4}$ Departamento de Zootecnia - UFV, Viçosa - MG. \\ ${ }^{5}$ FEAD - Belo Horizonte, MG. \\ ${ }^{6}$ Pós-graduação - Departamento de Zootecnia - UFV. \\ ${ }^{7}$ Departamento de Informática - UFV, Viçosa - MG.
}

RESUMO - Objetivou-se com este trabalho avaliar os efeitos da irrigação e da adubação com N e K sobre a disponibilidade e a qualidade da matéria seca em pastagem de capim-elefante cv. Napier adubada com N e K nas dosagens de 100:80; 200:160; 300:240 e 400:320 kg.ha-1 .ano $^{-1}$ de $\mathrm{N} \mathrm{e} \mathrm{K}_{2} \mathrm{O}$, respectivamente, no período seco do ano. Foram conduzidos dois experimentos (área irrigada - AI e não-irrigada - ANI), segundo delineamento de blocos casualizados com três repetições, em que a unidade experimental consistiu de parcelas (piquetes) de $300 \mathrm{~m}^{2}$, nas quais foram aplicados os tratamentos. No período de avaliação (maio a setembro/2001 - período seco), as disponibilidades de matéria seca total (DMST) e lâmina foliar (DMSLF) apresentaram valores proporcionais às doses de nitrogênio e potássio. A irrigação teve efeito significativo sobre a DMSLF. No entanto, os teores de FDN e FDA, ao longo do período seco, na área não-irrigada foram menores que na área irrigada. As concentrações de $\mathrm{PB}$ e dos macrominerais ( $\mathrm{P}, \mathrm{K}, \mathrm{Ca}$ e $\mathrm{Mg}$ ) não foram influenciadas pelas doses de $\mathrm{N}$ e $\mathrm{K}$ e pela irrigação, tanto na área irrigada como na não-irrigada.

Palavras-chave: adubação, composição bromatológica, gramínea tropical, Pennisetum purpureum

\section{Forage yield and quality of elephantgrass response to irrigation and nitrogen and potassium fertilization in the dry season}

ABSTRACT - An experiment was carried out in experimental plots of $300 \mathrm{~m}^{2}$ in size to evaluate the effects of doses of NK fertilization and irrigation on forage mass yield and quality of elephantgras cv Napier during the dry season. The experimental design was completely randomized with three treatment replications. The experimental treatments were arranged in a $4 \times 2$ factorial combination of four $\mathrm{N}-\mathrm{K}_{2} \mathrm{O}$ doses with and without irrigation, in the dry season. $\mathrm{N}-\mathrm{K}_{2} \mathrm{O}$ doses were: $100-80 ; 200-160 ; 300-240$ and 400-320 kg.ha-1, respectively. Figures for total dry forage mass (TDFM), and dry green leaf mass (DGLM) increased in proportion to $\mathrm{N}-\mathrm{K}_{2} \mathrm{O}$ dose from May to September 2001, the dry season period. Irrigation had a marked significant effect on DGLM yield. Leaf samples from irrigated plots had higher contents of neutral and acid detergent fiber as compared to leaf samples from the control plots. Concentrations of crude protein, potash, phosphorus, calcium and magnesium did not respond either to $\mathrm{N}-\mathrm{K}_{2} \mathrm{O}$ doses or to irrigation.

Key Words: chemical composition, fertilization, Pennisetum purpureum, tropicalgrass

\section{Introdução}

Na maioria das regiões brasileiras, a pecuária é explorada em sistemas de pastagem, de modo que, nos últimos dez anos, apenas $13 \%$ dos animais abatidos vieram de sistemas de confinamento, semiconfinamento ou de pastagens cultivadas com forrageiras de inverno (Anualpec, 2003). Grande parte dos animais abatidos é proveniente de pastagens estabelecidas em solos de baixa fertilidade natural, localizadas em área marginais, se comparadas às das culturas anuais para produção de grãos, o que tem contribuído para a baixa produtividade e qualidade da forragem, influenciando os índices de produção animal. Esses baixos índices de produtividade da pecuária têm estimulado a substituição das pastagens por outras culturas, observando-se, nos anos de 1969 a 1980, redução total de 1.094.921 ha para pecuária (Faria et al., 1996). Há previsão de que, nos próximos 10 anos, 24 milhões de ha de área de pastagens serão transformados em lavouras (Anualpec, 2003). 
Essa redução nas áreas de pastagens e a abertura do mercado internacional para a carne brasileira, com estimativas de crescimento de $170 \%$ em quantidade e de $250 \%$ em valores, permitirão salto na produção de carne de 1,3 milhões de t/ano para 2,5 milhões para o ano 2013. Esse incremento da produção de carne garantiria ao Brasil o título de maior exportador de carne bovina. Nos últimos 41 anos (1961 a 2002), o rebanho cresceu $214 \%$, ao passo que as áreas de pastagem aumentaram apenas $51 \%$, resultando em maior taxa de lotação, que passou de 0,46 para $0,95 \mathrm{cab} / \mathrm{ha}$ (FAO, 2002), o que é preocupante, visto que 50\% das áreas de pastagens apresentam algum grau de degradação (Zimmer et al., 1994), decorrente da falta de manejo adequado (taxa de lotação ajustada) e da ausência do uso de corretivos e fertilizantes.

Admite-se que, para reverter essa situação, devem ser adotados sistemas de produção que combinem o uso de tecnologias adequadas e de forrageiras de maior potencial produtivo, como Pennisetum purpureum, Panicum maximum e Brachiaria brizantha. Com o uso de suplementos alimentares e adubação de pastagens, será possível aumentar a produção e a produtividade do rebanho, sem comprometimento da sustentabilidade da cadeia produtiva.

O uso racional de fertilizantes é de grande relevância para maximização da eficiência econômica da atividade pecuária. Entre os macronutrientes, o nitrogênio e o potássio desempenham papel fundamental na nutrição das plantas e, portanto, são indispensáveis em sistema de utilização in tensiva do solo. O nitrogênio é constituinte essencial das proteínas e interfere diretamente no processo fotossintético, por participar na molécula de clorofila. O potássio é o cátion em maior concentração nas plantas e possui relevantes funções fisiológicas e metabólicas, como ativação de enzimas, fotossíntese, translocação de assimilados, absorção de nitrogênio e síntese protéica.

A irrigação também pode aumentar a produção e a qualidade da forragem, principalmente em regiões onde o inverno é seco e não há limitações climáticas e em locais com freqüência constantes de veranicos. Durand et al. (1997) e Morales et al. (1997) constataram expressivo aumento na taxa de alongamento de folhas $\left(\mathrm{TA}_{1} \mathrm{~F}\right)$ e na densidade de perfilhos. Esses autores observaram redução de aproximadamente $60 \%$ na $\mathrm{TA}_{1} \mathrm{~F}$ da haste principal quando a disponibilidade hídrica foi de $50 \%$, ressaltando-se que é difícil dissociar o efeito direto da limitação hídrica sobre as características de crescimento dos efeitos da menor disponibilidade de $\mathrm{N}$, que inevitavelmente se verifica nestas condições. Resposta similar foi verificada por Denardim (2001), em Briza subaristata, cujo valor para a TA $\mathrm{F}_{1}$ variou de 0,194 a $0,476 \mathrm{~mm} /{ }^{\circ} \mathrm{C}$, de acordo com a disponibilidade hídrica. Lemaire \& Chapman (1996) demonstraram que a densidade de perfilhos e a TAF influenciam no IAF e no rendimento forrageiro de gramíneas.

A irrigação por aspersão sob baixa pressão constitui, no entanto, alternativa para produção de forragem em quantidade e qualidade de forma regular e a baixo custo (Alencar, 2001). Assim, objetivou-se com este trabalho avaliar a disponibilidade e a qualidade da matéria seca do capim-elefante sob pastejo, com e sem irrigação, associado a diferentes doses de adubação nitrogenada e potássica no período seco do ano.

\section{Material e Métodos}

O experimento foi conduzido em Viçosa - MG, no setor de Forragicultura do Departamento de Zootecnia da Universidade Federal de Viçosa (UFV), em uma área de pastagem de capim-elefante (Pennisetum purpureum Schum. cv. Napier) estabelecida em 1998. Viçosa está localizada na Zona da Mata de Minas Gerais, a $651 \mathrm{~m}$ de altitude, $20^{\circ} 45^{\prime}$ de latitude sul e $42^{\circ} 51^{\prime}$ de longitude oeste. A temperatura média anual é de $19^{\circ} \mathrm{C}$, com média das máximas de $22,1^{\circ} \mathrm{C}$ e a média das mínimas de $15^{\circ} \mathrm{C}$. Porém, as temperaturas mínimas mensais para os meses de abril a setembro são inferiores a $15^{\circ} \mathrm{C}$ (Figura 1). A umidade relativa do ar é, em média, de $80 \%$ e a precipitação pluvial média anual, de $1.341 \mathrm{~mm}$, com estações seca e chuvosa bem definidas. O clima é classificado como Cwa, subtropical, com inverno ameno e seco.

As características químicas do solo, obtidas em amostras da camada 0-20 $\mathrm{cm}$ de profundidade, antes do plantio do capim-elefante e no início deste experimento, são apresentadas na Tabela 1.

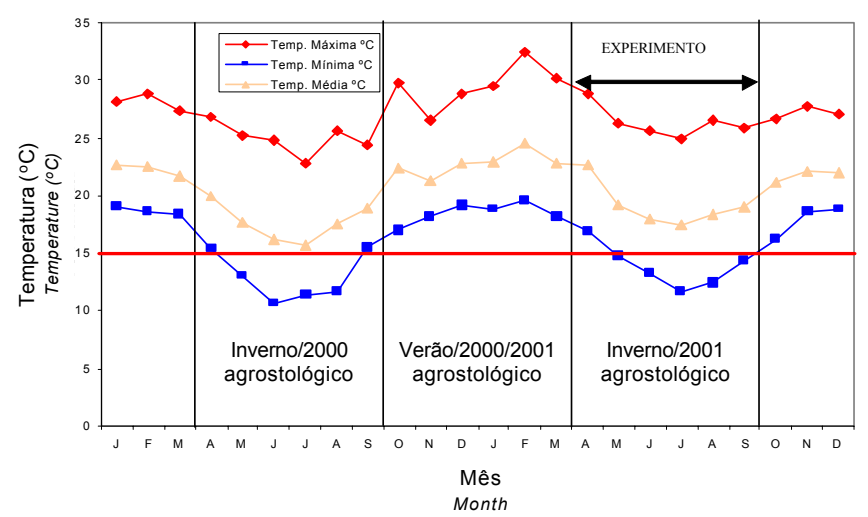

Figura 1 - Temperaturas mínimas, médias e máximas $\left({ }^{\circ} \mathrm{C}\right)$ mensais nos anos 2000 e 2001, Viçosa - MG.

Figure 1 - Mean, maximum and minimum monthly temperatures $\left({ }^{\circ} \mathrm{C}\right)$ during 2000 and 2001, Viçosa - MG 
O estudo consistiu de dois experimentos (uma área irrigada - AI e outra não-irrigada - ANI) em delineamento de blocos casualizados com três repetições. Os tratamentos consistiram da aplicação de quatro doses de $\mathrm{N}$ e K (100:80, 200:160, 300:240 e 400:320 kg.ha-1), em uma relação de 1:0,8, no período seco do ano (abril a setembro 2001). Embora ambos os experimentos tenham compreendido apenas o período seco do ano (abril a outubro de 2001), tiveram seu início no período das águas (outubro de 2000), com a aplicação de $100 \%$ da dose na ANI e $70 \%$ na AI, em três parcelas, a primeira no início (out/2000), a segunda no meio (dez/2000) e a terceira no final do período das águas (fev/2001), quando se utilizaram uréia e cloreto de potássio como fonte de nutrientes.

Este experimento é continuação das pesquisas desenvolvidas por Lopes (2001) e compreende apenas o período seco do segundo ano (abril a setembro de 2001). Portanto, quando se iniciou o experimento, $70 \%$ da dose de nitrogênio já havia sido aplicada na AI e 100\% na ANI. Na AI, houve $70 \%$ da adubação residual com mais $30 \%$ das doses dos tratamentos aplicados em dose única (abril/2001), enquanto, na ANI, ocorreu apenas o efeito residual das doses nitrogênio aplicadas por Lopes (2001) no período das águas.

A irrigação foi realizada por meio de um sistema de aspersão convencional de média pressão, manejada com turno de rega variável, usando-se o método do tanque
"Classe A" para estimativa da evapotranspiração de referência. A irrigação foi feita sempre que o valor do somatório da evapotranspiração real da cultura, subtraído da precipitação efetiva, fosse próximo ao valor da capacidade real de água no solo (CRA). Para cálculo da CRA, considerou-se a disponibilidade de água no solo igual 0,5.

Avaliaram-se dois ciclos de pastejo (pastejo rotativo), com três vacas por piquete $\left(300 \mathrm{~m}^{2}\right)$, durante três dias de ocupação, e os períodos de descanso necessários para as plantas atingirem altura média de $1,70 \mathrm{~m}$. No primeiro ciclo de pastejo, foram realizadas dez leituras de altura da planta (tomando o nível do solo até a altura média das folhas da extremidade dos perfilhos), além da estimativa de cobertura do solo na pastagem, em uma estimativa de 0 a $100 \%$, realizada por dois avaliadores com planilhas individuais. Logo após as leituras, foram realizados os cortes das plantas a 0,80 m do nível do solo. No segundo ciclo de pastejo, foram realizadas as mesmas dez leituras da altura e a estimativa da cobertura do solo, porém, em apenas cinco dos dez quadrados amostrados. Para os cinco pontos não amostrados, a produção de forragem foi estimada por meio de equações de regressão pré-determinadas ainda no primeiro ciclo de pastejo, que correlacionam a altura da planta $(\mathrm{cm})$ e a porcentagem de cobertura do solo (0 a $100 \%)$.

Coletaram-se duas subamostras representativas do primeiro ciclo e duas do segundo ciclo de pastejo. Destas

Tabela 1 - Análise química em amostras do solo da área experimental $(0-20 \mathrm{~cm})$ antes do início (abr/2000) e ao final (out/2001) do experimento, no período da seca

Table 1 - Chemical analysis in soil sample in the experimental area $(0-20 \mathrm{~cm})$ before the beginning (abr/2000) and at the end (out/2001) of the experiment in the dry season period

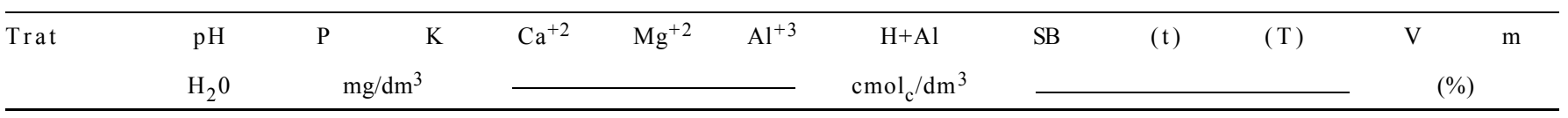

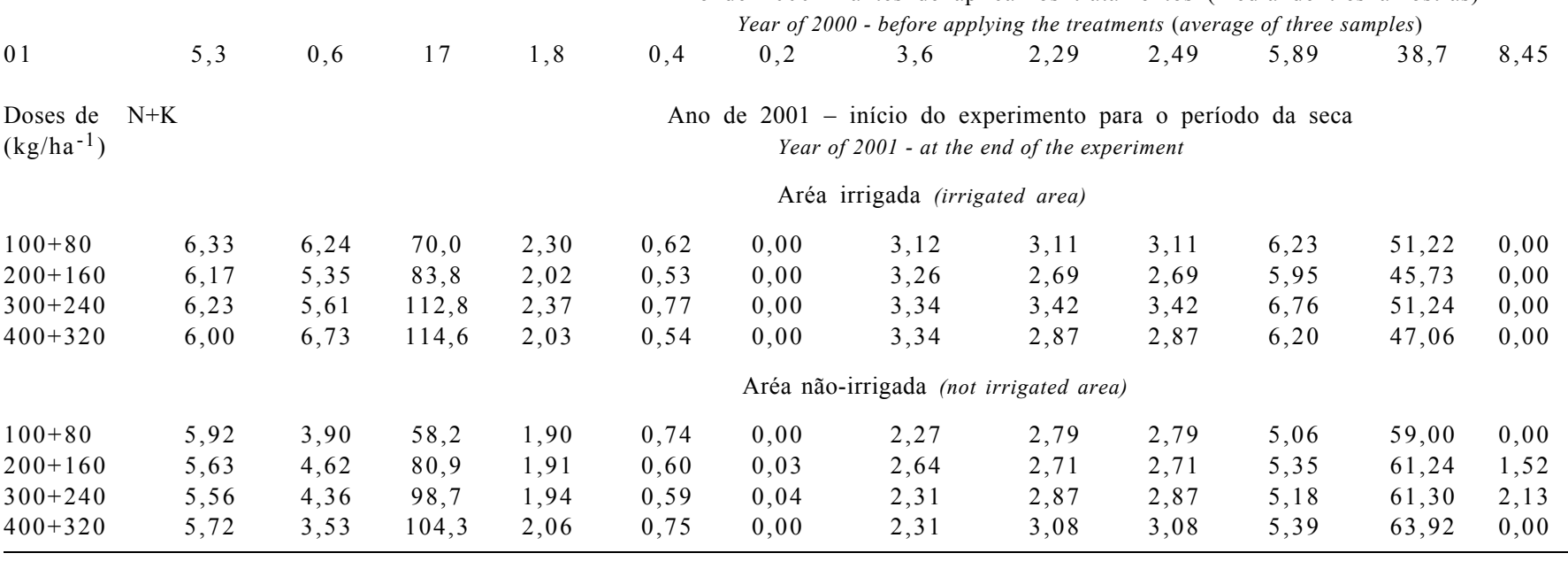

Fonte: Laboratório de análise de solo da Universidade Federal de Viçosa (UFV).

Source: Laboratory of soil analysis of the Federal University of Viçosa (UFV).

$\mathrm{pH}$ em $\mathrm{H}_{2} \mathrm{O}=$ Relação 1:2,5; $\mathrm{P}-\mathrm{K}=$ Extrator Mehlich-1; $\mathrm{Ca}-\mathrm{Mg}-\mathrm{Al}=$ Extrator: $\mathrm{KCl}-1 \mathrm{~mol} / \mathrm{L} ; \mathrm{H}+\mathrm{Al}=\mathrm{Extrator}$ acetato de cálcio $0,5 \mathrm{~mol} / \mathrm{L}-\mathrm{pH} 7.0$; $\mathrm{SB}=$ Soma de bases trocáveis; $(\mathrm{t})=$ Capacidade de troca catiônica efetiva; $(\mathrm{T})$ = Capacidade de troca catiônica a pH 7.0 ; $\mathrm{V}=$ Índice de saturação de bases; $\mathrm{m}=$ Índice de saturação de alumínio. 
subamostras, foram separadas as lâminas foliares do colmo (colmo+bainha) e levadas para a estufa de circulação forçada a $65^{\circ} \mathrm{C}$ por 72 horas.

Foram analisados os teores de MS, PB, FDN, FDA e macrominerais ( $\mathrm{P}, \mathrm{K}, \mathrm{Ca}$ e $\mathrm{Mg}$ ), conforme metodologia descrita por Silva \& Queiroz (2002), no Laboratório de Forragicultura da Universidade Federal de Viçosa-UFV, Viçosa - MG.

As análises estatísticas para cada experimento foram realizadas separadamente para o efeito de doses de $\mathrm{N}$ e K, com aplicação do teste Tukey a 5\% de probabilidade para as médias dos tratamentos e as características avaliadas. Posteriormente, efetuou-se uma análise conjunta para se avaliar o efeito da irrigação entre os dois experimentos, pelo teste $\mathrm{F}$ a $5 \%$ de probabilidade (UFV, 2001).

\section{Resultados e Discussão}

$\mathrm{O}$ uso de nutrientes $\mathrm{N}$ e $\mathrm{K}$ aumentou a disponibilidade de matéria seca total (DMST) $(\mathrm{P}<0,05)$, independentemente da irrigação (Tabela 2).

A ausência de efeito da irrigação sobre a DMST pode estar relacionada às altas taxas de alongamento do colmo de Pennisetum purpureum em relação a outras gramíneas tropicais. Desse modo, ao final de cada ciclo de pastejo, as folhas são consumidas pelos animais quase na sua totalidade, enquanto o colmo permanece na pastagem, compondo o resíduo pós-pastejo. Este efeito tende a ser cumulativo com a sucessão do número de ciclos ocorridos por ano.

Verificou-se também que este efeito de alongamento do colmo foi proporcional aos incrementos das doses $\mathrm{N}+\mathrm{K}$, tanto na $\mathrm{AI}$ como na ANI, de modo que, no período das águas que antecedeu o experimento atual, aplicou-se 100\% da adubação na ANI e 70\% na AI, resultando em maior resíduo pós-pastejo na ANI. Estes incrementos de resíduos pós-pastejo também foram observados em outras forrageiras de crescimento cespitoso, como o Panicum maximum (Cândido et al., 2005).

Assim, a altura de corte a $80 \mathrm{~cm}$ acima do solo, para avaliações da PMST (folha+colmo+material senescente) não foi eficiente para eliminar o efeito dos resíduos póspastejo dos ciclos anteriores sobre os deste experimento. $\mathrm{O}$ efeito do resíduo pós-pastejo cumulativo e de maior proporção na ANI provocado pelo manejo da adubação pode ser a principal causa da não-significância da irrigação $(\mathrm{P}<0,05)$, quando avaliada a partir da DMST (Tabela 2) entre a AI e ANI.

Em áreas sob pastejo adubadas com diferentes doses de $\mathrm{N}+\mathrm{K}$ e com plantas que elevam o colmo, como o capimelefante, seria mais recomendável a análise da disponi-
Tabela 2 - Disponibilidade de matéria seca total (DMST) nas áreas irrigada $(\mathrm{Al})$ e não-irrigada $(\mathrm{ANI})$ nas diferentes doses de $\mathrm{N}+\mathrm{K}$

Table 2 - Total dry matter availability (TDMA) in irrigated (IA) and not irrigated (NIA) areas at different $N+K$ doses

\begin{tabular}{lcc}
\hline $\begin{array}{c}\text { Dose de N+K } \\
N+K \text { dose }\end{array}$ & \multicolumn{2}{c}{$\begin{array}{c}\text { DMST } \\
\text { TDMA }\end{array}$} \\
\cline { 2 - 3 } & $\begin{array}{r}\text { Área irrigada (AI) Área não-irrigada (ANI) } \\
\text { Irrigated area (IA) }\end{array}$ Not irrigated area (NIA) \\
\hline \multicolumn{3}{c}{$\mathrm{t.ha}^{-1}$} \\
\hline $100+80$ & $14,26 \mathrm{~b}$ & $12,20 \mathrm{c}$ \\
$200+160$ & $17,15 \mathrm{a}$ & $17,16 \mathrm{ab}$ \\
$300+240$ & $21,38 \mathrm{a}$ & $20,31 \mathrm{a}$ \\
$400+320$ & $21,65 \mathrm{a}$ & $23,65 \mathrm{a}$ \\
Média & $18,61 \mathrm{~A}$ & $18,39 \mathrm{~A}$ \\
Mean & &
\end{tabular}

Médias, na coluna, seguidas de letras minúscula diferentes, ou na linha, seguidas deletras maiúsculas, são diferentes $(P<0,05)$ pelo testeTukey. Means, within a column, followed by different small letters, or in a row, followed by different capital letters differ $(P<0.05)$ by Tukey test.

bilidade da matéria seca da forragem pela fração das lâminas foliares (DMSTLF) que pela DMST. Outro fator importante é que as folhas remanescentes como resíduo póspastejo possuem período de senecência menor que o colmo, de forma que sua duração é menor que o próprio intervalo dos ciclos de pastejo, evitando o efeito do resíduo póspastejo, ocasionado por lâminas foliares sobre a variávelresposta analisada, e permitindo a avaliação da real produção em cada ciclo de pastejo.

Neste contexto, considerando-se apenas a fração da folha, constata-se que houve efeito significativo da irrigação sobre a AI e ANI (Tabelas 3 e 4), o que permite representar as condições visuais observadas a campo durante o período experimental, não observadas pela variávelresposta DMST (Tabela 2 ).

A disponibilidade de lâmina foliar foi influenciada $(\mathrm{P}<0,05)$ pelas doses nitrogênio e potássio, tanto na área irrigada como na não-irrigada, obtendo-se os maiores valores na área com irrigação (Tabela 4).

A disponibilidade de lâmina foliar $\left(\mathrm{t}^{\mathrm{h}} \mathrm{h}^{-1}\right)$ foi proporcional às doses dos fertilizantes nos dois experimentos, com valores variando de 5,32 a 9,38 na AI e de 3,14 a 7,16 na ANI (Tabela 4). O aumento na produção de lâminas foliares com a aplicação de fertilizantes e da irrigação também foi constatado por Andrade et al. (2000), Alvim et al. (2003) e Lopes et al. (2005).

A maior disponibilidade de lâminas foliares com os fertilizantes (Tabela 4) pode ser atribuída principalmente aos efeitos de $\mathrm{N}$ que potencializaram a taxa de reações enzimáticas e químicas no metabolismo da planta. Colozza et al. (2000) relataram que o maior teor de clorofila nas folhas aumentou a oferta de fotoassimilados e influenciou características 
morfogênicas como a taxa de alongamento da folha, a taxa de aparecimento de folha e a duração das folhas. Estas características influenciam o IAF, permitindo que a planta aumente a área de lâmina foliar fotossintética e, conseqüentemente, a produção de fotoassimilados e de matéria seca, o que resulta em maiores taxas de crescimento e desenvolvimento da planta (Lemaire \& Agnusdei, 1999). Portanto, a aplicação de $\mathrm{N}$, associada à disponibilidade adequada de outros nutrientes, pode contribuir para a redução no ciclo de colheita da forrageira e para maior produtividade de forragem.

Tabela 3 - Lâminas foliares na matéria seca total disponível (\% LFMSTD) nas áreas irrigada (AI) e não-irrigada (ANI), adubadas com diferentes doses de $\mathrm{N}+\mathrm{K}$, e médias da Al e ANI do capim-elefante sob pastejo

Table 3 - $\quad$ Percentage of leaf blade in the total dry matter availability (\% LBTDMA) in the irrigated (IA) and not irrigated (NIA) areas at different $N+K$ doses and average $I A$ and $A N I$ of elephantgrass under grazing

\begin{tabular}{lcc}
\hline $\begin{array}{c}\text { Dose de N+K } \\
N+K \text { dose }\end{array}$ & \multicolumn{2}{c}{$\begin{array}{c}\text { \%LFMSTD } \\
\% \text { LBTDMA }\end{array}$} \\
\cline { 2 - 3 } & $\begin{array}{c}\text { Área irrigada (AI) } \\
\text { Irrigated area (IA) }\end{array}$ & $\begin{array}{c}\text { Área não-irrigada (ANI) } \\
\text { Not irrigated area (NIA) }\end{array}$ \\
\hline & \multicolumn{2}{c}{$\%$} \\
\hline $100+80$ & $37,56 \mathrm{~b}$ & $24,33 \mathrm{~b}$ \\
$200+160$ & $42,48 \mathrm{ab}$ & $25,11 \mathrm{ab}$ \\
$300+240$ & $45,33 \mathrm{a}$ & $29,72 \mathrm{a}$ \\
$400+320$ & $43,90 \mathrm{a}$ & $28,46 \mathrm{ab}$ \\
Média & $42,32 \mathrm{~A}$ & \\
Mean & & \\
\hline
\end{tabular}

Médias, na coluna, seguidas de letras minúsculas diferentes, ou na linha, seguidas de letras maiúsculas, são diferentes $(P<0,05)$ pelo testeTukey. Means, within a column, followed by different small letters, or in a row, followed by different capital letters differ $(P<0.05)$ by Tukey test.

Tabela 4 - Disponibilidade de matéria seca total de lâmina foliares (DMSTLF) nas áreas irrigada ( $\mathrm{Al}$ ) e não-irrigada ( $\mathrm{ANI}$ ), adubadas com diferentes doses de $\mathrm{N}+\mathrm{K}$, e médias da Al e ANI do capim-elefante sob pastejo

Table 4 - Dry matter leaf blade availability (DMLBA) in irrigated area (IA) and not irrigated (NIA) at different $N+K$ doses and average IA and $A N I$ of elephantgrass under grazing

\begin{tabular}{lcc}
\hline $\begin{array}{l}\text { Doses de } \mathrm{N}+\mathrm{K} \\
N+K \text { dose }\end{array}$ & \multicolumn{3}{c}{$\begin{array}{c}\text { DMSTLF } \\
\text { DMLBA }\end{array}$} \\
\cline { 2 - 4 } & $\begin{array}{c}\text { Área irrigada (AI) } \\
\text { Irrigated area (IA) }\end{array}$ & $\begin{array}{c}\text { Área não-irrigada (ANI) } \\
\text { Not irrigated area (NIA) }\end{array}$ \\
\hline \multicolumn{3}{c}{$\mathrm{t.ha}^{-1}$} \\
\hline $100+80$ & $5,32 \mathrm{c}$ & $3,14 \mathrm{c}$ \\
$200+160$ & $7,20 \mathrm{bc}$ & $4,44 \mathrm{bc}$ \\
$300+240$ & $9,68 \mathrm{ab}$ & $6,48 \mathrm{ab}$ \\
$400+320$ & $9,38 \mathrm{a}$ & $7,16 \mathrm{a}$ \\
Média & $7,90 \mathrm{~A}$ & $5,30 \mathrm{~B}$ \\
Mean & & \\
\hline
\end{tabular}

Médias, na coluna, seguidas de letras minúsculas diferentes, ou na linha, seguidas de letras maiúsculas, são diferentes $(P<0,05)$ pelo testeTukey. Means, within a column, followed by different small letters, or in a row, followed by different capital letters differ $(P<0.05)$ by Tukey test.
Os teores de PB nas lâminas foliares do capim-elefante não foram influenciados $(\mathrm{P}>0,05)$ pelas doses de $\mathrm{N}$ e K aplicadas e pela irrigação.

Os teores médios de PB nas lâminas foliares do capimelefante foram de $12,3 \pm 0,24$ a 12,5 $\pm 0,50$, respectivamente, para AI e ANI (desvio-padrão). Ao considerar a produção de PB por área, os valores passaram de 644,5 para $1.192,2 \mathrm{~kg} \cdot \mathrm{ha}^{-1}$ na AI e de 368,3 para $910,0 \mathrm{~kg} \cdot \mathrm{ha}^{-1}$ na ANI, com a menor e a maior doses de $\mathrm{N}+\mathrm{K}$ aplicadas no período da seca de 2001 , demonstrando que a adubação com $\mathrm{N}+\mathrm{K}$ contribuiu para aumentar a produção de matéria seca e não afetou os teores de PB, como observado por Lopes et al. (2005) na AI.

Andrade et al. (2000), no entanto, combinaram doses menores de K com a adubação nitrogenada e constataram aumento nos teores de PB conforme as doses de N. O mesmo não se verificou quando combinaram doses maiores de $\mathrm{K}$ com N, sugerindo que os teores ou os incrementos de PB reduziram com as doses de $\mathrm{N}$. Os autores justificaram que a redução nos teores de $\mathrm{PB}$ deveu-se ao efeito de diluição na planta, ocasionado pelo incremento da produção de MS com a combinação de maiores doses de N e K. Entretanto, ao quantificarem a produção por área de $\mathrm{PB}$, a produção passou de 236 para $744 \mathrm{~kg}$.ha ${ }^{-1}$ de PB com o aumento das doses de $\mathrm{N}$ e $\mathrm{K}$ no período das águas.

Estudos realizados por Lambertucci et al. (2003) e Alvim et al. (2003) demonstraram que os teores de PB são reduzidos pelos incrementos de tecidos lignificados (com menores teores de $\mathrm{PB}$ ), resultantes do aumento nas doses de $\mathrm{N}$, que altera a morfologia dos perfilhos, como tamanho, largura, número e peso da folha (Casagrande et al., 2003) e relação folha/colmo no perfilho (Alvim et al., 2003).

Neste trabalho, a adubação com N e K permitiu maior eficiência no acúmulo de matéria seca que nas concentrações dos teores de PB na forragem com e sem irrigação. Constatou-se também que, ao adubar a pastagem com doses de $\mathrm{N}+\mathrm{K}$, não houve incremento nos teores de $\mathrm{PB}$, como observado por Lopes et al. (2005) na AI. Andrade et al. (2000), no entanto, verificaram redução nos teores de PB, demonstrando que o K pode estar limitando a eficiência na deposição de N na forragem.

O teores de FDN e FDA nas lâminas foliares de capimelefante não foram influenciados $(\mathrm{P}>0,05)$ pelas doses de $\mathrm{N}$ e $\mathrm{K}$, exceto os valores de FDN nas maiores doses de $\mathrm{N}$ e $\mathrm{K}$ na ANI. Por outro lado, a irrigação aumentou $(\mathrm{P}<0,05)$ tanto os teores de FDN como os de FDA na MS, que foram, respectivamente, de 73,93 $\pm 0,73$ e 72,45 $\pm 0,72$ e de $35,25 \pm 0,56$ e $32,75 \pm 0,63$, para AI e ANI.

A diferença na resposta sobre os teores de FDN nas lâminas foliares com os nutrientes aplicados foi registrada 
também por Lopes (2001), Mistura (2001), Silva et al. (2002) e Lambertucci et al. (2003) e pode ser explicada pela influência de $\mathrm{Ne} \mathrm{K}$ nas taxas de crescimento e desenvolvimento do capim-elefante, resultando em maior produção e tamanho de lâminas foliares (Tabela 4). Esse efeito decorre de mudanças nas características estruturais dos perfilhos, como folhas de maiores tamanho, que, em princípio, necessitam de maiores proporções de frações lignificadas, em razão da maior participação de nervura central na lâmina foliar, que apresenta maiores teores de FDN e FDA (Casagrande et al., 2003; Lambertucci et al., 2003). Incrementos nos teores de FDN e FDA também foram discutidos por Mistura (2001) e Lopes (2001), em plantas mais desenvolvidas de capim-elefante, e por Heringer et al. (2002), no milheto, quando aplicaram doses crescentes de $\mathrm{N}$ com fatores climáticos mais favoráveis em relação a este estudo. $\mathrm{O}$ fato de este trabalho ter sido conduzido em uma época em que a temperatura mínima foi limitante (inferior a $15^{\circ} \mathrm{C}$ ) em vários meses do ano (Figura 1) pode ter limitado a resposta para doses crescentes de N+K. Na ANI, as lâminas foliares de menor tamanho devem apresentar menor participação da nervura central e redução nos teores de FDN, como relatado por Barreto et al. (2001), quando submeteram quatro cultivares de capim-elefante a estresse hídrico. Entretanto, os menores teores de FDN verificados com as maiores doses de $\mathrm{N}+\mathrm{K}$ na ANI podem estar associados ao menor número de lâminas foliares com o início do processo de senescência.

Os teores de $\mathrm{P}, \mathrm{K}, \mathrm{Ca}$ e Mg na MS de lâmina foliares do capim-elefante não foram influenciados $(\mathrm{P}>0,05)$ pela adubação ou pela irrigação, provavelmente em razão do baixo crescimento e desenvolvimento das forrageiras tropicais no inverno, atribuídos por Ferreira (1998) à deficiência hídrica, ao fotoperíodo mais curto e às baixas temperatura noturnas no inverno. Segundo Whitheman (1980), as espécies de clima tropical produzem muito pouco quando expostas a temperaturas inferiores a $16^{\circ} \mathrm{C}$ e, neste trabalho, durante quase todo o período experimental, a temperatura mínima esteve abaixo desse limite crítico (Figura 1).

Os teores médios de $\mathrm{P}$ na MS das lâminas foliares para a AI foi de $0,24 \pm 0,01$ e na ANI, de $0,20 \pm 0,01$. Santos Jr. et al. (1999) observaram redução de $72 \%$ na absorção de fósforo em quatro cultivares de braquiária submetidos ao estresse hídrico. Todavia, apesar da ausência de efeito significativo da adubação sobre os teores de $\mathrm{P}$ nas lâminas foliares do capim-elefante entre a AI e ANI, constata-se que, na ANI, os teores críticos de $6 \mathrm{mg} \cdot \mathrm{dm}^{-3} \mathrm{de} P$ no solo necessários para não limitar a difusão do nutriente pelas raízes estão aquém dos registrados por Cantarutti et al. (1999).

Os teores médios de $\mathrm{P}$ nas lâminas foliares do capimelefante sob irrigação, nas diferentes doses de $\mathrm{N}+\mathrm{K}$, atendem às necessidades de várias categorias animais, inclusive vacas em lactação (Senger et al., 1996), enquanto os obtidos na ANI são suficientes apenas para vacas secas e novilhos em crescimento.

Os teores médios de K na MS das lâminas foliares, de acordo com as doses de $\mathrm{N}+\mathrm{K}$, foram de 2,56 $\pm 0,11$ na $\mathrm{AI}$ e de 2,68 $\pm 0,12$ na $\mathrm{ANI}$. Embora não tenha sido observada diferença $(\mathrm{P}>0,05)$, ao se multiplicarem os teores médios ajustados pela disponibilidade de MS total das lâminas foliares, verificou-se conteúdo de K de 202,24 e 142,04 kg.ha-1 na AI e ANI, respectivamente.

A ausência de efeito significativo de adubação sobre os teores de $\mathrm{K}$ na planta pode ser explicada pelos elevados teores de nutrientes disponíveis no solo no início deste estudo (Tabela 1). Por outro lado, Castro \& Mengheli (1989) e Rosolem (1990), em solos com baixos e altos teores de K trocável, também não encontraram resposta da aplicação de $\mathrm{K}$ sobre os teores deste nutriente na planta.

Segundo o NRC (1996), os teores de 0,60 a $0,80 \%$ de potássio na MS são mínimos para atender às necessidades de bovinos em pastejo, enquanto, para o metabolismo do potássio em ruminantes, recomenda-se $0,50 \%$ como limite crítico na dieta. Assim, em todos os tratamentos, os teores de $\mathrm{K}$ nas lâminas foliares do capim-elefante atenderiam plenamente às necessidades mínimas dos animais.

Os teores médios de Ca na MS das lâminas foliares do capim-elefante não diferiram $(\mathrm{P}>0,05)$ entre as doses de $\mathrm{N}+\mathrm{K}$, tanto na AI quanto na ANI e entre os sistemas (AIxANI). (Tabela 7). Entretanto, o conteúdo de Ca nas lâminas foliares na $\mathrm{AI}\left(89,3 \mathrm{~kg} \cdot \mathrm{ha}^{-1}\right)$ foi superior ao da ANI $\left(63,1 \mathrm{~kg} \cdot \mathrm{ha}^{-1}\right)$, como conseqüência do maior acúmulo de MS produzida.

Os teores médios de Ca nas lâminas foliares do capimelefante foram de $1,13 \pm 0,05$ na AI e de $1,19 \pm 0,04$ na ANI, bem superiores ao nível crítico de 0,40 estabelecido por Salinas \& Sanchez, citados por Gomide (1990), bem com os de 0,$25 ; 0,26 ; 0,33 ; 0,51$ relatados, respectivamente, por Mistura (2001), Almeida et al. (2000), Acunha \& Coelho (1997) e Souza Filho et al. (1988).

Os teores médios de magnésio na MS das lâminas foliares foram de $0,33 \pm 0,03$ na AI e 0,31 $\pm 0,04$ na ANI. Ausência de efeito da adubação com $\mathrm{N}$ e K sobre os teores de Mg na planta também foi observada por Ribeiro et al. (1999) e Vicente-Chandler et al. (1959a), em capim-elefante cv. Napier. Entretanto, Gomide et al. (1984a) e Mistura (2001) constataram incrementos proporcionais às doses de $\mathrm{N}$, enquanto Mendonça et al. (2003) verificaram redução nos teores de $\mathrm{Mg}$ com as doses de $\mathrm{N}$.

Embora os teores de Mg na MS não se encontrem bem definidos na literatura, para evitar riscos de deficiência 
desse nutriente em plantas forrageiras, Woodson, citado por Neptune (1986), recomenda níveis acima de $0,20 \%$ na MS da planta. Gallo et al. (1974) constataram variações de 0,13 a $0,46 \%$, com valor médio de $0,24 \%$, em 149 amostras de nove forrageiras tropicais em São Paulo, de 0,14 a $0,46 \%$, com média de $0,27 \%$, em capim-elefante.

Considerando-se esses resultados e os de outros autores (Vicente-Chandler et al., 1959 a, b; Caro Costa et al., 1960, Gomide et al., 1984b; Palhano \& Haddad, 1992; Acunha \& Coelho, 1997), nota-se que os teores de Mg registrados neste estudo são superiores às exigências dos animais, de 0,20 a $0,25 \%$ (NRC, 2001).

Constatou-se maior extração $\left(\mathrm{kg} \cdot \mathrm{ha}^{-1}\right)$ de $\mathrm{P}, \mathrm{K}, \mathrm{Ca}$ e Mg na AI, como conseqüência da maior disponibilidade de MS de lâminas foliares do capim-elefante. Ao analisar os teores dos nutrientes no solo, verificaram-se maiores valores de $\mathrm{P}$, K e Ca na AI (Tabela 1), o que indica que, na AI, o sistema pode ter maior sustentabilidade, em razão da maior reciclagem dos nutrientes, decorrente dos maiores teores de carbono no solo e das menores densidades do solo em relação à ANI, como demonstrado por Pegoraro et al. (2003a,b). Por outro lado, a irrigação, além de aumentar a produção de MS, garante processo contínuo de mineralização da $\mathrm{MO}$ residual, disponibilizando minerais, reduzindo o caráter-dreno do solo, principalmente de $\mathrm{P}$ (Novais \& Smyth, 1999), como constatado por Pegoraro et al. (2003a) na camada de $0-5 \mathrm{~cm}$, em que os maiores teores de carbono orgânico proporcionaram maior disponibilidade de P para as plantas na AI (Tabela 1).

\section{Conclusões}

A associação da adubação nitrogenada e potássica incrementou a disponibilidade de matéria seca da parte área da planta e das lâminas foliares e não influenciou os teores de proteína bruta, fibras, fósforo, potássio, cálcio e magnésio.

A irrigação contribuiu para elevar os teores de fibra em detergente neutro e ácido nas lâminas foliares, sem alterar os teores de proteína bruta, fósforo, potássio, cálcio e magnésio.

\section{Literatura Citada}

ACUNHA, J.B.V.; COELHO, R.W. Efeito da altura e do intervalo de corte do capim-elefante anão. I. Produção e qualidade de forragem. Pesquisa Agropecuária Brasileira, v.32, n.1, p.117-122, 1997.

AGUIAR, A.P. A irrigação de pastagens no Brasil. URL: http:// www.cpt.com.br/revista/mattec/0221.asp. 07/10/2001

ALENCAR, C.A.B. Pastagem e cana-de-açúcar, irrigados por aspersão de baixa pressão. In: SIMPÓSIO DE PRODUÇÃO DE GADO DE CORTE, 2., 2001, Viçosa, MG. Anais... Viçosa, MG: Universidade Federal de Viçosa, 2001. p.233-242.

ALMEIDA, E.X.; MARASCHIN, G.E.; HARTHMANN, O.E.L. et al. Oferta de forragem de capim-elefante anão "Mott" e o rendimento animal. Revista Brasileira de Zootecnia, v.29, n.5, p.1288-1295, 2000.

ALVIM, M.J.; BOTREL, M.A.; REZENDE, H. et al. Avaliação sob pastejo do potencial forrageiro de gramíneas do gênero Cynodon, sob dois níveis de nitrogênio e potássio. Revista Brasileira de Zootecnia, v.32, n.1, p.47-54, 2003.

ANDRADE, A.C.; FONSECA, D.M.; GOMIDE, J.A. et al. Produtividade e valor nutritivo do capim-elefante cv. Napier sob doses crescentes de nitrogênio e potássio. Revista Brasileira de Zootecnia, v.29, n.6, p.1589-1595, 2000.

ANUÁRIO ESTATÍSTICO DA PECUÁRIA DE CORTE. São Paulo: FNP, v.11, 2003.

BARRETO, G.P.; LIRA, M.A.; SANTOS, M.V.F. et al. Avaliação de clones de capim-elefante (Pennisetum purpureum Schum.) e de um híbrido com o milheto (Pennisetum glaucum (L.) submetidos a estresse hídrico. 2. Valor Nutritivo. Revista Brasileira de Zootecnia, v.1, n.30, p.7-11, 2001

CÂNDIDO, M.J.D.; GOMIDE, C.A.; ALEXANDRINO, E. et al. Morfofisiologia do dossel de Pannicum maximum cv. Mombaça sob lotação intermitente com três períodos de descanso. Revista Brasileira de Zootecnia, v.34, n.2, p.406-415, 2005.

CANTARUTTI, R.B.; MARTINS, C.E.; CARVALHO, M.M. et al. Pastagens. In: RIBEIRO, A.C.; GUIMARÃES, P.T.G.; ALvareZ, V. (Eds.) Comissão de fertilidade do solo do Estado de Minas Gerais: recomendação para o uso de corretivos e fertilizantes em Minas Gerais - $5^{\text {a }}$ Aproximação. Viçosa, MG: 1999. p.332-341.

CARO-COSTAS, R.; VICENTE-CHANDLER, J.; FIGARELLA, J. The yields and composition of five grasses growing in the humid mountains of Puerto Rico as affected by nitrogen fertilization, season, and harvest procedures. Journal of Agriculture University Puerto Rico, v.44, n.3, p.107-120, 1960.

CASAGRANDE, D.R.; MISTURA, C.; FONSECA, D.M. et al. Característica estruturais de perfilhos em pastagem de capimelefante adubado com nitrogênio. In: REUNIÃO ANUAL DA SOCIEDADE BRASILEIRA DE ZOOTECNIA, 40., Santa Maria, 2003. Anais... Santa Maria: Sociedade Brasileira de Zootecnia, 2003, Forrageiras, (1 CD-ROM).

CASTRO, A.F.; MENEGHELLI, N.A. As relações $\mathrm{K}^{+} /\left(\mathrm{Ca}^{++}+\right.$ $\left.\mathrm{Mg}^{++}\right) 1 / 2 \mathrm{e} \mathrm{K}^{+} /\left(\mathrm{Ca}^{++}+\mathrm{Mg}^{++}\right)$no solo e as respostas a adubação potássica. Pesquisa Agropecuária Brasileira, n.24, p.751-760, 1989

COLOZZA, M.T.; KIEHL, J.C.; WERNER, J.C. et al. Produção de matéria seca, concentração de nitrogênio e teor de clorofila em Panicum maximum cv. Aruana adubado com nitrogênio. In: REUNION LATINOAMERICANA DE PRODUCCION ANIMAL, 16., CONGRESO URUGUAYO DE PRODUCION ANIMAL, 3., 2000, Montevideo. Anais... Montevideo, Uruguay: Asociacion Latinoamerica de Producion Animal (ALPA), 2000, Forrageiras, (1 CD-ROM).

DENARDIM, R.B.N. Avaliação morfogênica e agronômicas de gramíneas hibernais, nativas do Rio Grande do Sul. Porto Alegre: Universidade Federal do Rio Grande do Sul, 2001. 215 p. Tese (Doutorado em Zootecnia) - Universidade Federal do Rio Grande do Sul, 2001.

DURAND, J.L.; GASTAL, F.; ETCHEBEST, S. et al. Interespecific variability of plant water status and leaf morphogenesis in temperate forage grasses under summer water deficit. European Journal of Agronomy, v.7, p.99-107, 1997.

FARIA, V.O.; PEDREIRA, C.G.S.; SANTOS, P.A.P. Evolução do uso de pastagem para bovinos. In: SIMPÓSIO SOBRE MANEJO DE PASTAGEM, 13., 1996, Piracicaba. Anais.... Piracicaba: Fundação de Estudos Agrários Luiz de Queiroz, 1996, p.1-14.

FERREIRA, J.J. Alternativas de suplementação e valor nutritivo do capim-elefante sob pastejo rotacionado. Informe Agropecuário, v.19, n.192, p.66-72, 1998.

FOOD AND AGRICULTURE ORGANIZATION OF THE UNITED NATIONS. Disponível em: http//www.fao.org. Acesso em: maio de 2002. 
GALLO, J.R.; HIROCE, R.; BATAGLIA, O.C. et. al. Composição química orgânica de forrageira do Estado de São Paulo. Boletim da Industria Animal, v.31, n.1, p.115-137, 1974

GOMIDE, J.A. Formação e utilização de capineira de capim-elefante. In: SIMPÓSIO SOBRE CAPIM-ELEFANTE, 1990, Juiz de Fora. Anais... Coronel Pacheco: Embrapa Gado de Leite, 1990. p.58-87.

GOMIDE, J.A.; COSTA, G.G.; SILVA, M.A.M.M. et al. Adubação nitrogenada e consorciação de capim-colonião e capim-jaraguá com leguminosa. I. Produtividade e teor de nitrogênio das gramíneas e das misturas. Revista Sociedade Brasileira de Zootecnia, v.13, n.1, p.10-21, 1984a.

GOMIDE, J.A.; LEÃO, M.I.; OBEID, J.A. et al. Avaliação de pastagens de capim-colonião e capim-jaraguá. Revista da Sociedade Brasileira de Zootecnia, v.13, n.1, p.1-9, 1984b.

HERINGER, I.; MOOJEN, E.L. Potencial produtivo, alterações da estrutura e qualidade da pastagem de milheto submetida a diferentes níveis de nitrogênio. Revista Brasileira de Zootecnia, v.31, n.2, p.875-882, 2002

LAMBERTUCCI, D.M.; MISTURA, C.; FONSECA, D.M. et al. Qualidade de diferentes frações da lâmina foliar em pastagem de capim-elefante adubada com nitrogênio. In: REUNIÃO ANUAL DA SOCIEDADE BRASILEIRA DE ZOOTECNIA, 40., Santa Maria, 2003. Anais... Santa Maria, RS: Sociedade Brasileira de Zootecnia, 2003, Forrageiras, (1 CD-ROM)

LEMAIRE, G.; AGNUSDEI, M. Leaf tissue turn-over and efficiency of herbage utilization. In: GRASSLAND ECOPHYSIOLOGY AND GRAZING ECOLOGY, 1999, Curitiba. Proceedings... Curitiba, Universidade Federal do Paraná, 2000. p.265-288.

LEMAIRE, G.; CHAPMAN, D. Tissue fluxes in grazing plant communities. In: HODGSON, J.; ILliUS, AW. (Eds.). The ecology and management of grazing systems. Wallingford: CAB International, 1996. p.3-36.

LOPES, R.S. Adubação nitrogenada e potássica em pastagens de capim-elefante sob irrigação. Viçosa, MG: Universidade Federal de Viçosa, 2001. 107p. Tese (Doutorado em Zootecnia) - Universidade Federal de Viçosa, 2001.

LOPES, R.S.; FONSECA, D.M.; OLIVEIRA, A.O. et al. Efeito da irrigação e adubação na disponibilidade e composição bromatológica da massa seca de lâminas foliares de capim-elefante. Revista Brasileira de Zootecnia, v.34, n.1, p.20-29, 2005.

MENDONÇA, B.P.C.; MISTURA, C.; FONSECA, D.M. et al. Composição mineral em diferentes frações da lâmina foliar de capim-elefante adubado com nitrogênio. In: REUNIÃO ANUAL DA SOCIEDADE BRASILEIRA DE ZOOTECNIA, 40., Santa Maria, 2003. Anais... Santa Maria, RS: Sociedade Brasileira de Zootecnia, 2003, Forrageiras, (1 CD-ROM)

MISTURA, C. Doses crescentes de nitrogênio e fósforo na produção e qualidade do capim elefante anão (Pennisetum purpureum Schum.) cv. Mott. Pelotas: Universidade Federal de Pelotas, 2001. 88p. Dissertação (Mestrado em Zootecnia) Universidade Federal de Pelotas, 2001.

MORALES, A.S.; NABINGER C.; MARACHIN, G.E. et al. Efeito da disponibilidade hídrica sobre a morfogênese e a repartição de assimilados em Lotus corniculatus L. cv. São Grabriel. In: REUNIÃO ANUAL DA SOCIEDADE BRASILEIRA DE ZOOTECNIA, 34., 1997, Juiz de Fora. Anais... Juiz de Fora, MG: Sociedade Brasileira de Zootecnia, 1997 (1 CD-ROM).

NATIONAL RESEARCH COUCIL - NRC. Nutrient requirements of beef cattle. 7.ed. Washington, D.C.: National Academy of Science, 1996. 242p.

NATIONAL RESEARCH COUNCIL - NRC. Nutrient requirements of dairy cattle. 7.ed. Washington, D.C.: Academic Press, 2001. 381p.

NEPTUNE, A.M.L. Aplicação de calcário em culturas forrageiras. In: PEIXOTO, A.M.; MOURA, J.C.; FARIA, V.P. (Eds.) Pastagens: fundamentos da exploração racional. Piracicaba: Fundação de Estudos Agrários Luiz de Queiroz, 1986. p.73-107.

NOVAIS, R.F.; SMYTH, T.J. Fósforo em solo e planta em condições tropicais. 1.ed. Viçosa, MG: Universidade Federal de Viçosa, 1999. 399p.
PALHANO, A.L.; HADDAD, C.M. Recrutamento de nutrientes e valor nutritivo de Cynodon dactylon (L.) Pers. cv. Coast-cross N1. Pesquisa Agropecuária Brasileira, v.27, n.10, p.14291438, 1992.

PEGORARO, R.F.; MISTURA, C.; WENDLING, B. et al. Densidade e carbono orgânico do solo influenciados por doses de nitrogênio sob pastejo de capim-elefante irrigado. In: REUNIÃO ANUAL DA SOCIEDADE BRASILEIRA DE ZOOTECNIA, 40., 2003, Santa Maria. Anais... Santa Maria: Sociedade Brasileira de Zootecnia, 2003a (1 CD-ROM).

PEGORARO, R.F.; WENDLING, B.; MISTURA, C. et al. Efeito de doses de nitrogênio na densidade de carbono orgânico do solo em pastagem de capim-elefante. In: REUNIÃO ANUAL DA SOCIEDADE BRASILEIRA DE ZOOTECNIA, 40., 2003, Santa Maria. Anais... Santa Maria: Sociedade Brasileira de Zootecnia, 2003b (1 CD-ROM).

RIBEIRO, K.G.; GOMIDE, J.A.; PACIULLO, D.S.C. Adubação nitrogenada do capim-elefante cv. Mott. 2. Valor nutritivo ao atingir 80 e $120 \mathrm{~cm}$ de altura. Revista Brasileira de Zootecnia, v.28, n.6, p.1194-1202, 1999.

ROSOLEM, C.A.; NAKAGAWA, J. Residual and annual potassic fertilization for soybeans. Nutrient Cycling in Agroecosystem, n.59, p.143-149, 1990.

SANTOS JR., J.D.G.; KANNO, T.; UOZUMI, S. et al. Eficiência na absorção de fósforo em quatro espécies de Brachiaria submetidas ao estresse hídrico. In: REUNIÃO ANUAL DA SOCIEDADE BRASILEIRA DE ZOOTECNIA, 36., Porto Alegre, 1999. Anais... Porto Alegre: Sociedade Brasileira de Zootecnia, 1999, Forrageiras (1 CD-ROM).

SENGER, C.C.D.; SANCHEZ, L.M.B.; PIRES, M.B.G.; et al. Teores minerais em pastagens do Rio Grande do Sul. I. Cálcio, fósforo, magnésio e potássio. Pesquisa Agropecuária Brasileira, v.31, n.12, p.897-904, 1996.

SILVA, J.S.; QUEIROZ, A.C. Análise de alimentos: métodos químicos e biológicos. 3.ed. Viçosa: Editora UFV, 2002. 235p.

SILVA, L.F.A.; LEITE, G.G.; ARAÚJO, K.V. et al. Energia digestível e digestibilidade aparente da fibra em detergente neutro e em detergente ácido do capim-elefante (Pennisetum purpureum SCHUM.) por eqüinos. In: REUNIÃO ANUAL DA SOCIEDADE BRASILEIRA DE ZOOTECNIA, 39., 2002, Recife. Anais... Recife: Sociedade Brasileira de Zootecnia, 2002 (1 CD-ROM).

SOUZA FILHO, A.P.S.; ROCHA, G.P.; EVANGELISTA, A.R. et al. Efeito da maturidade sobre a produção e qualidade de folhas e colmos do capim-elefante Pennisetum purpureum cv. Dwarf. Ciência e Prática, v.12, n.2, p.189-199, 1988.

UNIVERSIDADE FEDERAL DE VIÇOSA - UFV. SAEG - Sistema de análises estatísticas e genéticas. Versão 7.1 Viçosa MG: 1997, 301p. (Manual do usuário).

VICENTE-CHANDLER, J.; SILVA, S.; FIGUEIRA, J. Effect of nitrogen fertilization and frequency of cutting on the yield and composition of Guinea grass in Puerto Rico. Journal of Agricultural University Puerto Rico, v.43, n.4, p.229-38, 1959a.

VICENTE-CHANDLER, J.; SILVA, S.; FIGUEIRA, J. Effect of nitrogen fertilization and frequency of cutting on the yield and composition of Napier grass in Puerto Rico. Journal of Agricultural University Puerto Rico, v.43, n.4, p.215-227, 1959b.

ZIMMER, A.H.; MACEDO, M.C.M.; BARCELLOS, A.O. et al. Estabelecimento e recuperação de pastagens de Brachiaria. In: SIMPÓSIO SOBRE MANEJO DE PASTAGEM, 11., 1994, Piracicaba. Anais.... Piracicaba: Fundação de Estudos Agrários Luiz de Queiroz, 1994. p.153-208. 